Research Article

\title{
The Model of the Relationship between Urban Rail Transit and Residential Location
}

\author{
Lin Zhang (D) \\ School of Economics \& Management, Nanchang Hangkong University, Nanchang 330063, Jiangxi, China \\ Correspondence should be addressed to Lin Zhang; 773651827@qq.com
}

Received 15 May 2020; Revised 22 June 2020; Accepted 3 July 2020; Published 4 August 2020

Academic Editor: Tingsong Wang

Copyright (C) 2020 Lin Zhang. This is an open access article distributed under the Creative Commons Attribution License, which permits unrestricted use, distribution, and reproduction in any medium, provided the original work is properly cited.

\begin{abstract}
In order to investigate the intrinsic relationship between residence choice and urban rail transit, this paper establishes a housing valuation model, explores the interface link between the rail transit and other transport modes by the establishment of a model, and also obtains the family transportation impedance. According to the balanced housing price, the various districts' hedonic cost, and the generalized transportation impedance, the attractiveness of the various districts with respect to each mobile home is obtained. Satisfaction of any resident is received by establishing a close degree model. Due to the satisfaction and the price, we construct a largest consumer surplus model and then obtain the residence of the greatest consumer surplus for mobile home. Numerical example's result indicates that all high-income mobile homes will chose the residence for the commute destination district, especially the one in the suburbs. Furthermore, the low-income families chose the residence for the commute destination district, which has the rail transit if the income is allowed, or the nearest district to the destination with rail transportation if not. This illustrates that whether a road having urban rail transit plays a significant impact only on the low-income family residence choice when the commuter routes pass through the road and almost has no influence for other families. Hence, it is shown that the reasonable urban planning is important and that urban rail transit should form a network that will play a key role.
\end{abstract}

\section{Introduction}

There are different types of land use, including industrial land, commercial land, and residential land, where the residential land is the main factor that influences the traffic volume and is also the generated point of traffic demand for industrial land and commercial land in the rush hours. Since the contradiction between supply and demand of urban traffic is more intensive along with the rapid urbanization, urban rail transit becomes the preferred large-capacity public transport to relieve the traffic pressure in large city due to its characteristics of being safe, speedy, highly efficient, energy-saving, and environment-friendly. Noting that the large city pays much more attention to the scale of rail transit construction, it is meaningful to study the model of the inner relationship between the choice of residential location and the rail transit, which could provide quantitative methods to guide the orderly growth of the urban space and thus guarantee the relationship between urban space and urban traffic to be interaction and coordination. It is well-known that there are four kinds of land-use transport integration model: the space interaction model (Enjian and Takayuki; Li et al.) $[1,2]$, the mathematical programming model (Chang and Mackett; Tao et al.; Zhen) [3-5], the random utility model (Chandra and Jessica; Pinjari et al.; Earnhart; Zhen) [6-9], and the bid-rent model (Zhang) [10]. The spatial interaction model distributes the employment and residential location into different zones of the region by considering the distances between the zones and their attractiveness by the force of gravity or entropy. There have been huge literature studies on the application of the spatial interaction models. Wagener [11] established an operational gravity model of spatial interactions, which can be used for urban region, and also defined a framework for the classification and evaluation of urban land use. Roy and Thill [12] demonstrated the interactions between various economic fields and land use, encompassing the environmental, technological, economic, and regulatory factors that affect 
land use with a larger scope. Silveira and Dentinho [13] have discussed the relationships between activities and zones based on relative accessibilities, bid-rents, capacities, and technical coefficients through a spatial interaction model. They adjusted the bid-rents for each activity per zone and achieved the equilibrium between supply and demand for each activity per zone. Later, Dentinho and Silveira [14] divided each zone of the city into fourteen soil classes and applied the calibration of the bid-rents to depict conflicts of different activities through the estimated factors of attractiveness in the same soil class. Residents of the different zones were attracted to each other through the weight factor of various soil classes. The advantage of the space interaction model is that it has a simple concept and then is easy to understand. However, this type of model did not illustrate both the features of the location and the decision process of the family. Moreover, this model was descriptive in nature and did not consider explicitly the interaction between transportation and land use.

The mathematical programming model is designed to generate the optimal position of the family, which has been studied intensively in the past. For example, Anas et al. [15-17] developed the mathematical programming model to discuss the congestion tolls in city. The authors divided the urban space into multiple zones and used the general equilibrium to evaluate the influence with and without the tolls policy. They presented that a congestion toll would have an impact on labor supply and also the productivity by changing the labor-leisure trade off. Such a toll could cause workers to work less and thus allocate more time to leisure. Murphy [18] has utilized linear programming to provide insights into the relationship between the location of commuting and housing. The results show that the pattern of relative location advantage has altered sharply for off-peak trip-making but has remained more or less the same for tripmaking in the peak period. The mathematical programming model is the combination of the space interaction model and the traffic distribution model and emphasizes the integration between transportation and land use. But the credibility of the results of the mathematical programming model is somewhat questionable due to the lack of the behavioral factors of the decision-makers and the simplicity assumptions on the huge number of modeling conditions.

The random utility model describes the interactions between transportation and the household active area by the household utility maximization principle. The theoretical foundation generally stems from the microeconomic theory; e.g., Jun [19] evaluates the impact of medium- and highincome households' preference for apartments on residential location choice by constructing a random utility-based landuse simulation model of the Seoul metropolitan area. Then, Jun [20] investigates the redistributive effects of Seoul's bus rapid transit system on development patterns and property values by using an urban simulation model. This model is the combination of the Seoul metropolitan input-output model with random utility-based location choice models and endogenous real estate markets. For the improved transportation system with new household and employment distribution patterns, Kelvin et al. [21] discussed residential and job allocations in the system through the reliabilitybased network design problem and made a reliability-based land-use and transportation model for the integrated residential and job allocations and transportation network design problem. Coppola and Nuzzolo [22] gave an activities-location choice model with endogenous price which simulates, based on expected random utility principle, the behavior of several agents of the urban system to estimate the spatial distribution of socioeconomic activities within the study area as well as the impact of differential changes in accessibility on the dwelling price. A disequilibrium-based random utility modeling framework is developed for the built space markets by Farooq and Miller [23]. This framework is then used for the Greater Toronto and Hamilton Area's owner-occupied housing market within integrated land-use transportation and environment modeling system. In summary, the random utility model describes the location characteristics and the behavior utility effectively, but the model needs to be extended with more detailed household categories, and the description of the interaction process between transportation and land use is not clear.

The bid-rent model obtains the ideal location by the auction bidding process. For example, Kantor et al. [24] extend a traffic congestion external effect that adds a degree of freedom to the shape of the bid-rent curves and allows them to coincide over contiguous locations in the city where commuting takes place. Based on the bid-rent theory, Zhou and Kockelman [25] examine microscopic equilibrium of the single-family residential land development. Ma and Lo [26] formulated a nested multinomial logit model that combined with the bid-rent process to model residents' location and travel choices. Chong and Shui [27] examine how the rental differential between two locations in a metropolis is determined by the time value of a household. Models of this type are under the assumption that firms and residents compete for land, which is occupied by the agent offering the highest bid. Land rent is then equal to the highest bid. The bid mechanism is coordinated to the decision-making behavior about family location, but it is difficult to establish a clear functional relationship between land use and transportation.

The purpose of this paper is to explore the relationship between the rail transit and residential location. We establish some mathematical models to combine the optimization with the bid-rent. Based on the remaining maximum principle of the household consumption, the influence degree of rail transit where the residents choose residential location is analyzed quantitatively, and the details of the behavior where the residents choose residential location are also explained.

\section{Housing Valuation Model}

2.1. Estimation of Land Price. The housing is a commodity that can be consumed, and its price is mainly related to facility structures, traffic accessibility, structure characteristics of housing, the public service quality of the area, adjacent region characteristics, local residents' consumption 
level, etc. One can divide a city into several districts, which is denoted by the following set:

$$
D=\left\{1,2, \ldots, d_{0}\right\},
$$

where $d_{0}$ is the number of the districts in the city. Some of these districts contain (only one) rail transit station, and others do not contain the rail transit station. Let

$$
D^{\prime} \subseteq D,
$$

where $D^{\prime}$ is set of the districts, containing rail transit station. Any district $k \in D$ is made up of two types of families: one type is family who is ready to move their residence and wish to purchase or rent house in another district, and the other type is family who does not hope to move its residence to other district, which contains moving families within the district.

At the period time of $t$, such as one year or two years, let

$$
N_{0}^{k t}=N_{1}^{k t} \cup N_{2}^{k t},
$$

where $N_{0}^{k t}$ is the set of present living families in the k-th district. $N_{1}^{k t}$ is the set of families in the k-th district that do not move their residence to other districts and $N_{2}^{k t}$ is the set of families that are ready to move their residence to other districts.

At the period time of $t$, we assume that the amount of money for purchasing a house is allocated to each day (according to 20-year terms), which is the same as the daily rent of a house. In what follows, the land price and house price are also allocated to daily amount. Let $N_{3}^{k t}$ be the set of homeowners in the k-th district, renting or selling house to other district residents. For any $j \in N_{3}^{k t}, H_{j}^{k}$ is the set of houses ready to be rent or sold and belongs to homeowner $j$ in the $k$-th district, and, for any $m \in H_{j}^{k}$, the transaction price by which moving family $i$ purchases the house $m$ should satisfy

$$
p_{j m}^{k t} \geq V_{j m}^{k t}
$$

where $p_{j m}^{k t}$ is the transaction price of house $m$ belonging to homeowner $j$ in the k-th district at the period time of $t$ and $V_{j m}^{k t}$ is the cost of house $m$ belonging to homeowner $j$ in the $k$-th district at the period time of $t . V_{j m}^{k t}$ is consisted by land price of the k-th district and construction cost of house $m$ (including publicity expenses); that is,

$$
V_{j m}^{k t}=V^{k}+J,
$$

where $V^{k}$ is the land price of the $\mathrm{k}$-th district and $J$ is the construction price of house $m$.

Let $h^{k}$ be the completeness of hedonic facilities in the district $k$ that satisfies

$$
0<\varepsilon^{0} \leq h^{k} \leq 1,
$$

where $h^{k}=\varepsilon^{0}$ is the hedonic facilities completeness of the worst district, which is generally the one at the edge of the city. Let $h^{k}=1$ be the completeness of hedonic facilities in the center of city. $h^{k}$ is related to the business area of shopping center, famous schools within the district, the completeness of hedonic facilities in the adjacent district, and other factors. Under the condition of the vehicle with free-flow speed, we denote the traffic impedance from the district $k$ to the center of city by $u^{k}$. The land price $V^{k}$ is determined by both $h^{k}$ and $u^{k}$ of the district $k$; that is, $V^{k}$ is the function of $h^{k}$ and $u^{k}$. Since the land price of district is positively proportional to the hedonic facilities completeness of the district and the traffic accessibility from the district to the center of city, we thus define $V^{k}$ as follows:

$$
V^{k}=V^{0} h^{k}-c_{0} \beta u^{k},
$$

where $V^{0}$ is the land price of city center which is associated with the consumption level of residents, $c_{0}$ is the proportionality coefficient, and $\beta$ is the urban per capita income level per hour (calculated by five workdays in a week and 8 hours in a weekday).

Supposing that there are only two kinds of houses for sale or for rent, one is high-end and the other is mid-range. Assuming that the land price of same district and the construction costs $J$ of same grade housing are constants and the different grades housing construction costs are different from each other, denote

$$
J=\delta J^{1}+(1-\delta) J^{2},
$$

where $J^{1}$ and $J^{2}$ are the construction costs of high-end house and mid-grade one, respectively, and $\delta$ is the $0-1$ function satisfying $\delta=1$ if homeowner $j$ 's house for sale or for rent is high-end and $\delta=0$ if not. In summary, we can conclude that

$$
V_{j m}^{k t}=V^{k}+J=V^{0} h^{k}-c_{0} \beta u^{k}+J .
$$

2.2. Evaluation Model of the House. At the period time of $t$, assume that there are a certain number of families in any district that hope to move their residence to another district for improvement on the overall effectiveness of family housing, environment, traffic conditions, and so on. It means that each moving family wishes to buy an ideal residence. For any family $i$, which is ready to move its residence, it will give an evaluation $M_{i j m}^{k t}$ to sale or rent house $m$ that belonging to homeowner $j$ in the district $k$, and the family $i$ and the homeowner $j$ will reach an agreement under the condition of $p_{j m}^{k t} \leq M_{i j m}^{k t}$. Using formula (9), we can get $M_{i j m}^{k t}$ as follows:

$$
M_{i j m}^{k t}=\frac{\left[\left(\alpha M^{0}-J\right) h^{k}-c_{0} \beta u^{k}+J\right]}{\alpha},
$$

where $M^{0}$ is the evaluation of house in the city center and $\alpha$ is the occupancy of the house cost within $M^{0}$ which satisfies $0<\alpha \leq 1$; that is,

$$
\alpha M^{0}=V^{0}+J .
$$

\section{Traffic Impedance}

In order to relax the people for living and employment from the city center, we should promote rail transit station to link up with conventional public transport, motor vehicles, nonmotor vehicles, and pedestrians and thus form an urban traffic network, 
where rail transit is complement with other transportation systems and shares complementary advantages. From the point of view of traffic impedance, choice of residence is traffic impedance compromise, that is, the main activities of family members, but it is not necessarily the optimal choice of each member of the family. Let $A_{i}$ be the set of $i$ - th family members; for any $a_{i} \in A_{i}, \Omega_{a_{i}}^{i h}$ is the average hourly income of member $a_{i}$, $\mathfrak{I}$ is the ratio of commuting cost per unit time to $\Omega_{a_{i}}^{\text {ih }}$ for $a_{i}, s_{a_{i}}$ is the main destinations, and $\zeta_{a_{i}}$ is the frequency by which $a_{i}$ goes to $s_{a_{i}}$ every day. Moreover, $r_{i}$ is the location of the $i$ - th family, $\mu_{1}$ represents the fare for the conventional public transport, and $\mu_{2}$ represents the fare for rail transit. $\mu_{3}$ represents a bicycle storage costs, $\mu_{4}$ represents the parking fee for a car, and $\mu_{5}$ represents the fuel costs per kilometer for a car. Finally, assuming that the family member $a_{i}$ goes to $s_{a_{i}}$ at the rush hours every day, the traffic impedance of one return is the same, if $a_{i}$ arrives the conventional public transport station or rail transit station outside in the destination, then it is arriving the destination $s_{a_{i}}$.

\subsection{Traffic Impedance of Self-Driving. Let}

$$
G=(V, E)
$$

be the urban traffic network, where $V$ is a finite-points set and $E$ is the directed-road set. Regarding each district as a point in the network, we denote by $R \subset V$ and $S \subset V$ the origin set and the destination one, respectively. For any $r \in R$ and $s \in S$, we use $q^{r s}$ to be the traffic demand from the origin $r$ to the destination $s$ and then have

$$
q^{r s}=\sum_{p \in p^{r s}} f_{p}^{r s}
$$

where $p^{r s}$ is the path set from $r$ to $s, p$ is one of the paths, and $f_{p}^{r s}$ is the OD pair traffic flow volume from $r$ to $s$ on the path $p$. For any directed road $a \in E$, the OD pair traffic flow volume from $r$ to $s$ on the directed road $a$ can be obtained as

$$
f_{a}^{r s}=\sum_{p \in p^{r s}} f_{p}^{r s} \delta_{a p}^{r s}
$$

where $\delta_{a p}^{r s}$ is the 0-1 function that satisfies $\delta_{a p}^{r s}=1$ if $a \in p$ and $\delta_{a p}^{r s}=0$ if not. Hence, the traffic flow volume on the directed road $a$ can be expressed as

$$
f_{a}=\sum_{r \in R} \sum_{s \in S} f_{a}^{r s}
$$

Let $v_{a}\left(f_{a}\right)$ be the vehicle speed on the road $a$ when the traffic flow volume is $f_{a}$; the time for the vehicle passing the path $p$ can be obtained as

$$
t_{p_{r s}}=\sum_{a \in p}\left(\frac{l_{a}}{v_{a}\left(f_{a}\right)}+\tau_{a}\right),
$$

where $p_{r s}$ is a path of the OD pair between $r$ and $s, l_{a}$ is length of the road $a$, and $\tau_{a}$ is the time the vehicle needs to pass the intersection at the end of the directed road $a$. Thus, the total generalized commuting transport cost for the $i-$ th family members $a_{i}$ driving the car from $r_{i}$ to $s_{a_{i}}$ on the path $p$ can be obtained as follows:

$$
c_{p_{r_{i} a_{a_{i}}}}=2 \zeta_{a_{i}} t_{p_{r_{i} a_{a_{i}}}} \mathfrak{\Im} \Omega_{a_{i}}^{i h}+2 \mu_{5} \sum_{a \in p} l_{a} .
$$

Here (and in what follows), we have calculated the cost of commuting for the back and forth on the road.

\subsection{Traffic Impedance of Conventional Public Transport.} Let

$$
G^{\prime}=\left(V^{\prime}, E^{\prime}\right)
$$

be the network for conventional public transport in the city, where $V^{\prime}$ is the set of conventional public transport stations and $E^{\prime}$ is the set of the directed roads for conventional public transport between two adjacent stations (could be a curve). Let $P^{/}$be the conventional public transport routes set; we denote by $V_{p^{\prime}}^{\prime}$ the set of all stations on $p^{\prime}$ for any conventional public transport route $p^{\prime} \in P^{\prime}$ and by $p_{r^{\prime} s^{\prime}}^{\prime}$ the conventional public transport path between station $r^{\prime}$ and station $s^{\prime}$ on the bus route for any stations $r^{\prime}, s^{\prime} \in V_{p^{\prime}}^{\prime}$; that is, $p_{r^{\prime} s^{\prime}}^{\prime} \subset p^{\prime}$.

For any bus road $a^{\prime} \in E^{\prime}$ with $a^{\prime}$ being the bus road between two adjacent conventional public transport stations, we denote the length of $a^{\prime}$ by $l_{a^{\prime}}$. Furthermore, let $V_{p_{r^{\prime} / s^{\prime}}^{\prime}}^{\prime}$ be the set of all conventional public transport stations set on the bus path $p^{\prime}$ between $r^{\prime}$ and $s^{\prime}$, let $B_{p_{r^{\prime} /}^{\prime}}$ be intersections set on the bus path $p^{\prime}$ between $r^{\prime}$ and $s^{\prime}$, and let $\tau_{\theta}$ be the time required for vehicle to pass the intersection $\theta$ for any $\theta \in B_{p_{r^{\prime} /}^{\prime}}$. If $r^{\prime} \in p^{\prime}, s^{\prime} \in q^{\prime}$ for any $p^{\prime}, q^{\prime} \in P^{\prime}$, and $p^{\prime} \cap q^{\prime}=g^{\prime}$ with $g^{\prime} \in V^{\prime} ; p_{r^{\prime} g^{\prime}}^{\prime} \cup q_{g^{\prime} s^{\prime}}^{\prime}$ is thus the conventional public transport path between station $r^{\prime}$ and station $s^{\prime}$, which is still named as the conventional public transport path and denoted by $p_{r^{\prime} s^{\prime}}^{\prime}$ for simplicity. Now, we propose some assumptions as follows: citizens in the city can reach their destinations at most once transfer by the conventional public transport; the buses' traveling speed is the same as the other vehicles' on the road between two stations at this time; the total delay of the conventional public transport is $\tau_{\rho}^{\prime}$ minutes for deceleration, up and down the passengers and acceleration at the station $\rho \in V^{\prime}$. Under the assumptions stated above, the traffic impedance of conventional public transports between $r^{\prime}$ and $s^{\prime}$ can be deduced as 


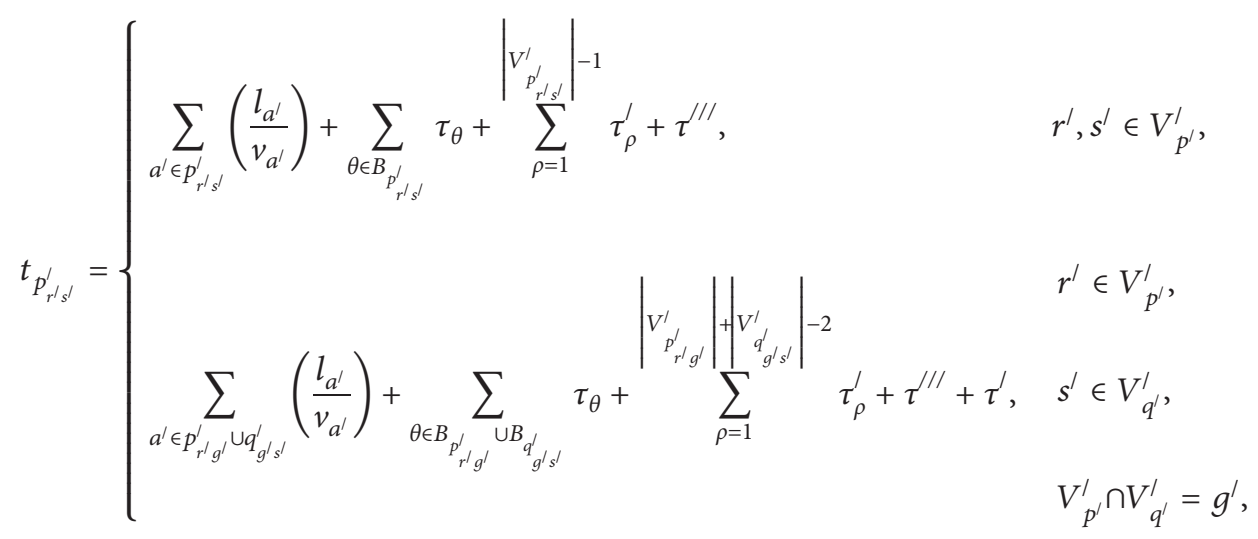

where $|\cdot|$ is the element number of set, $\tau^{\prime}$ is the waiting time for the passenger transfers between the conventional public transports, and $\tau^{\prime \prime \prime}$ is the time for waiting conventional public transport at the origin. Thus, the total generalized commuting traffic cost of the $i$-th family members $a_{i}$ by the conventional public transport from $r_{i}$ to $s_{a_{i}}$ can be expressed as

$$
c_{p_{r_{i} s_{a_{i}}}}=2 \zeta_{a_{i}} t_{p_{r_{i} s_{a_{i}}}} \Im \Omega_{a_{i}}^{i h}+2 \zeta_{a_{i}} \mu_{1} .
$$

\subsection{Traffic Impedance of Rail Transit. Let}

$$
G^{\prime \prime}=\left(V^{\prime \prime}, E^{\prime \prime}\right)
$$

be the network for rail transit in the city, where $V^{/ /}$is the set of rail transit stations and $E^{/ /}$is the set of directed channels for rail transit between two adjacent stations. Let $P^{/ /}$be routes set of the rail transit, for any rail transit route $p^{\prime \prime} \in P^{/ /}, V_{p^{\prime \prime}}^{\prime \prime}$ is the set of all stations on the rail transit route $p^{\prime \prime}$, for any stations $r^{\prime \prime}, s^{\prime \prime} \in V_{p^{\prime \prime}}^{\prime \prime}, p_{r^{\prime \prime}}^{\prime \prime} s^{\prime \prime}$ is the rail transit path between stations $r^{\prime \prime}$ and $s^{\prime \prime}$ on the rail transit route $p^{\prime \prime}$, and
$V_{p^{\prime \prime}}^{\prime \prime} \quad$ is the set of all stations on the rail transit route $p_{r^{\prime \prime}}^{\prime \prime} s^{\prime \prime}$. Assume that passenger can change at most once from one station to another in the rail transit network, and the station satisfies the shortest transfer which is achieved by the same station transfers, the same hall transfers, or the channel transfer, etc. Moreover, let $\tau^{/ /}$be the time for the transfer waiting when changing the rail transit. If stations $r^{\prime \prime} \in p^{\prime \prime}$ and $s^{\prime \prime} \in q^{\prime \prime}$ for any $p^{\prime \prime}, q^{\prime \prime} \in P^{\prime \prime}$ and $p^{\prime \prime} \cap q^{\prime \prime}=g^{\prime \prime}$ with $g^{\prime \prime} \in V^{\prime \prime}, p_{r^{\prime \prime}}^{\prime \prime} g^{\prime \prime} \cup q_{g^{\prime \prime} s^{\prime \prime}}^{\prime \prime}$ is thus the rail transit path between rail transit stations $r^{\prime \prime}$ and $s^{\prime \prime}$. Let $v_{a^{\prime \prime}}$ be the travel speed of train between each two adjacent rail stations on the directed channel $a^{\prime \prime}$, let $l_{a^{\prime \prime}}$ be the length of track channel $a^{\prime \prime}$, and let $\tau_{\sigma}^{/ /}$be the stopping time of rail transit at the station $\sigma$; if $a_{i}$ enters the subway platform from the entrance of the rail transit station $r^{\prime /}$, then it takes the rail transit to reach the station $s^{\prime \prime}$ by the line $p^{\prime \prime}$ and finally gets out of the station $s^{\prime \prime}$; we can get the traffic impedance of $a_{i}$ from entering the rail transit station $r^{/ /}$to getting out of the rail transit station $s^{\prime \prime}$ as

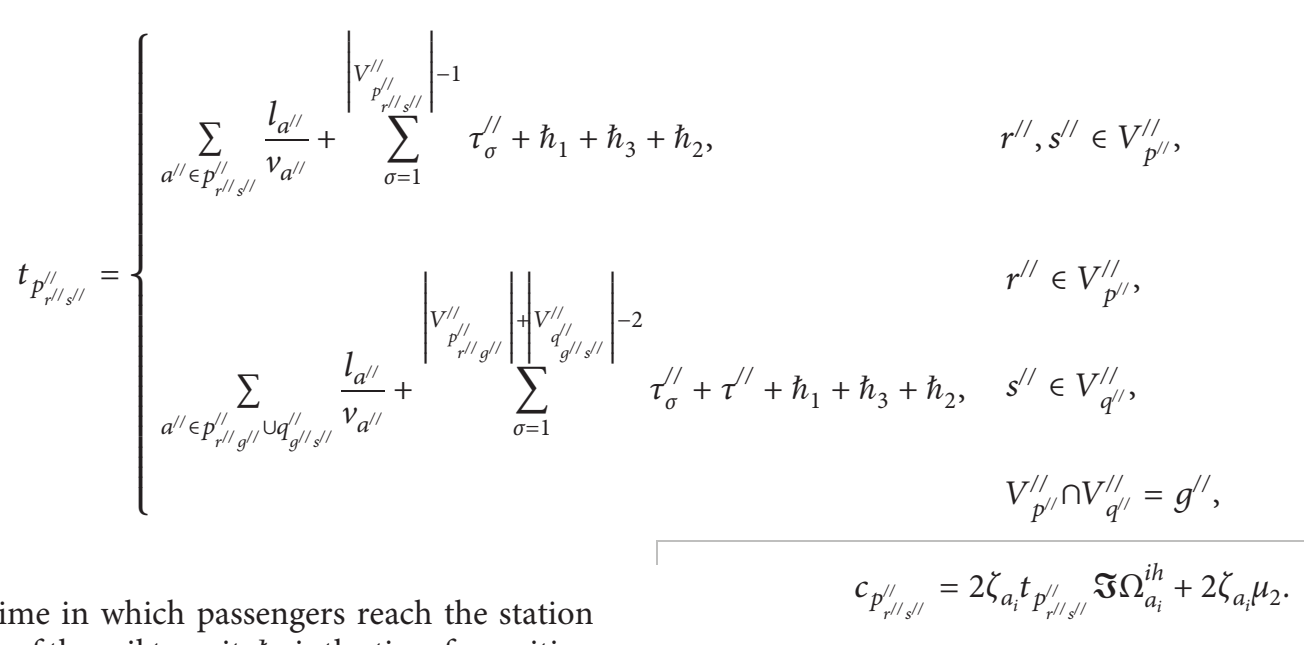

where $\hbar_{1}$ is the time in which passengers reach the station from the entrance of the rail transit, $\hbar_{3}$ is the time for waiting for the train, and $\hbar_{2}$ is the time for exiting the station. Thus, the total generalized commuting traffic cost of the $i-$ th family members $a_{i}$ by the rail transit line $p^{\prime \prime}$ from entering $r^{\prime /}$ to going out of $s^{/ /}$can be expressed as
3.4. Rail Transit Linking Up with Other Transportation Modes. Urban rail transit plays key role in the urban transport system, whose high accessibility promotes that the regional 
economic activity will be attracted to rail transportation corridor. Urban rail transit should have an effective connectivity and coordination with other transportation modes. This may form an integrated urban passenger transport system in which the rail transit is the backbone.

\subsubsection{The Traffic Connection Where One End of Rail Transit} Is Walking and the Other End Is Conventional Public Transport. Good walking environment must be effective within a certain walking scale. In general, a circle, whose center is the station and the semidiameter is $600 \mathrm{~m}$, could be regarded as attraction area of walking. Let $r / /$ be a rail transit station; the impedance that the $i$-th family walks to $r^{/ /}$within the walking attraction area of rail transit station $r^{/ /}$can be read as

$$
t^{i b}=\frac{l}{v_{1}},
$$

where $l$ is the distance between the $i-$ th family and rail transit station and $v_{1}$ is the average speed of walking. We can get from formula (23) that the total generalized commuting transport cost for the $i-$ th family members $a_{i}$ waling to rail transit station $r^{/ /}$followed by going to $s^{/ /}$by rail transit and finally exiting the station $s^{/ /}$can be expressed as

$$
c_{r^{\prime / s} s^{\prime /}}^{i b a_{i}}=2 \zeta_{a_{i}} t^{i b} \Im \Omega_{a_{i}}^{i h}+c_{p_{r^{\prime / / s} / /}^{\prime \prime}} .
$$

If the location of the $i$ - th family is within the walking attraction area of rail transit station $r^{/ /}$, using formulas (20) and (25), we can get the total generalized commuting transport cost for the $i$ - th family members $a_{i}$ walking to rail transit station $r^{/ /}$from $r_{i}$ followed by going to $s^{/ /}$by rail transit and exiting the station $s^{/ /}$and finally going to $s_{a_{i}}$ by conventional public transport, which can be expressed as

$$
c_{r^{\prime /} s^{\prime /} s_{a_{i}}}^{i b a_{i}}=c_{r^{\prime / s} s^{\prime / /}}^{i b a_{i}}+c_{p_{s / / s_{a_{i}}^{\prime}}^{\prime}} .
$$

\subsubsection{The Traffic Connection Where One End of Rail Transit} Is Bicycle and the Other End Is Conventional Public Transport. Since the attraction distance of bicycle is 600 2000 $\mathrm{m}$ from the rail transit station, we will focus our study on the ring area whose center is the rail transit station and the semidiameter is $600 \sim 2000 \mathrm{~m}$, and thus we conclude that the traffic impedance from the $i-$ th family to rail transit station $r^{/ /}$by bicycle is

$$
t^{i c}=\frac{l}{v_{2}},
$$

where $v_{2}$ is the average speed for riding a bicycle. If the location of the $i$ - th family is within the bicycle attraction area of rail transit station $r^{/ /}$, we can conclude from formula (23) that the total generalized commuting transport cost for the $i$ - th family members $a_{i}$ to ride a bicycle to rail transit station $r^{/ /}$followed by going to $s^{/ /}$by rail transit and finally exiting the station $s^{/ /}$can be expressed as

$$
c_{r^{\prime \prime} s^{\prime \prime}}^{i c a_{i}}=2 \zeta_{a_{i}} t^{i c} \mathfrak{\Im} \Omega_{a_{i}}^{i h}+\mu_{3} \zeta_{a_{i}}+c_{p_{r / s / l}^{\prime \prime}} .
$$

According to formulas (20) and (28), we can get that the total generalized commuting transport cost for the $i-$ th family members $a_{i}$ to ride a bicycle from home to rail transit station $r^{/ /}$followed by going to $s^{/ /}$from $r^{/ /}$by rail transit and finally going to $s_{a_{i}}$ by conventional public transport on the bus path $p^{\prime}$ can be expressed as

$$
c_{r^{\prime /} s^{\prime /} s_{a_{i}}}^{i c a_{i}}=c_{r^{\prime /} s^{\prime /}}^{i c a_{i}}+c_{p_{s^{\prime /} / s_{a_{i}}^{\prime}}} .
$$

\subsubsection{The Traffic Connection Where Both Ends of Rail Transit} Station Are Conventional Public Transport. By virtue of formulas (20) and (23), it is known that the total generalized commuting transport cost for the $i$ - th family members $a_{i}$ to reach rail transit station $r^{/ /}$from $r_{i}$ by conventional public transport followed by going to $s^{/ /}$by rail transit and finally exiting the station $s^{/ /}$can be obtained as

$$
c_{r_{i} r^{\prime /} s^{\prime /}}^{i d a_{i}}=c_{p_{r_{i} r / l}}+c_{p_{r^{\prime / /} / /}^{\prime \prime}} \text {. }
$$

Using formulas (20) and (30), the total generalized commuting transport cost for the $i$ - th family members $a_{i}$ to get to rail transit station $r^{/ /}$from $r_{i}$ by conventional public transport followed by going to $s^{/ /}$from $r^{/ /}$by rail transit and finally going to $s_{a_{i}}$ by conventional public transport can be deduced:

$$
c_{r_{i} r^{\prime /} s^{\prime /} s_{a_{i}}}^{i d a_{i}}=c_{r_{i} r^{\prime / s} s^{\prime /}}^{i d a_{i}}+c_{p_{s / / s_{a_{i}}}^{\prime}}
$$

3.4.4. The Traffic Connection Where One End of Rail Transit Is Car and the Other End Is Conventional Public Transport. According to formulas (17) and (23), we can know that the total generalized commuting transport cost for the $i-$ th family members $a_{i}$ to reach rail transit station $r^{/ /}$from $r_{i}$ by driving car followed by going to $s^{/ /}$by rail transit and finally exiting the station $s^{/ /}$can be derived as

$$
c_{r_{i} r^{\prime / s} s^{\prime /}}^{i e a_{i}}=c_{p_{r_{i} r /}}+\mu_{4}+c_{p_{r^{\prime / s} s /}^{\prime \prime}} .
$$

By formulas (20) and (32), the total generalized commuting transport cost for the $i$ - th family members $a_{i}$ to get to rail transit station $r^{/ /}$from $r_{i}$ by driving car followed by going to $s^{/ /}$from $r^{/ /}$by rail transit and then exiting the station $s^{/ /}$and finally going to $s_{a_{i}}$ by conventional public transport can be expressed as

$$
c_{r_{i} r^{\prime / s} s^{\prime /} s_{a_{i}}}^{i e a_{i}}=c_{r_{i} r^{\prime / s} s^{\prime /}}^{i e a_{i}}+c_{p_{r^{\prime /} / s_{a_{i}}}^{\prime}} .
$$

3.5. Generalized Transportation Costs of the Family. In general case, the private car owners will drive to the destination unless the generalized commuting transport cost of private car is much more than the generalized commuting transport cost of conventional public transport. Hence, assume that the car does not transfer to conventional public transport separately, and the private car owners will switch to other transportation modes to go the destination when the generalized commuting transport cost of private car is $\varpi$ 
times in comparison to the other transportations $(₫>1)$; we will consider the generalized transport cost of the $i-$ th family members $a_{i}$ going to the main destinations $s_{a_{i}}$ from $r_{i}$, which is denoted by $c_{r_{i} s_{a_{i}}}$, in the following four different cases:
(1) If the district where $r_{i}$ locates contains rail station $r^{\prime \prime}$ and the district where $s_{a_{i}}$ locates contains rail station $s^{\prime \prime}$, it follows from formulas (17), (20), (25), and (28) that

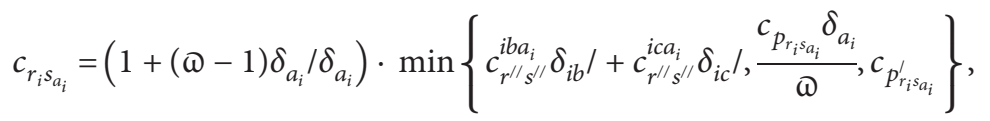

where $\delta_{i b} /$ is the $0-1$ function satisfying $\delta_{i b} /=1$ if the location of the $i$ - th family is within the walking attraction range of $600 \mathrm{~m}$ and $\delta_{i b} /=0$ if not, $\delta_{i c} /$ is the $0-1$ function satisfying $\delta_{i c} l=1$ when the location of the $i$ - th family is within the ring region of the bicycle attraction range of $600 \sim 2000 \mathrm{~m}$ of rail transit and $\delta_{i c} /=0$ otherwise, $\delta_{a_{i}}$ is the 0-1 function satisfying $\delta_{a_{i}}=1$ if $a_{i}$ has private car and $\delta_{a_{i}}=0$ if not, and $\delta_{a_{i}} /$ is the $0-1$ function satisfying $\delta_{a_{i}} /=1$ if the $i$ - th family members $a_{i}$ drive to the destination and $\delta_{a_{i}} I=0$ if not.

(2) If the district where $r_{i}$ locates contains rail station $r^{\prime \prime}$ and the district where $s_{a_{i}}$ locates does not contain rail station $s^{\prime \prime}$, we can get from formulas (17), (20), (26), and (29) that

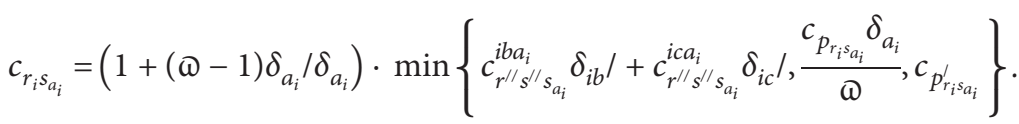

(3) If the district where $r_{i}$ locates does not contain rail station $r^{\prime /}$ and the district where $s_{a_{i}}$ locates does not contain rail station $s^{\prime \prime}$, we obtain after using formulas (17), (20), (31), and (33) that

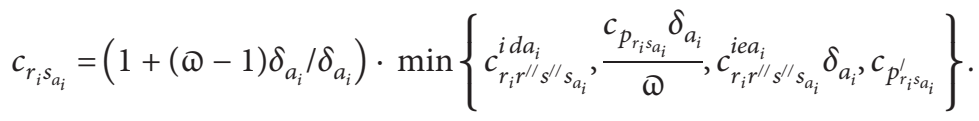

(4) If the district where $r_{i}$ locates does not contain rail station $r^{/ /}$and the district where $s_{a_{i}}$ locates does not contain rail station $s^{\prime \prime}$, it follows from formulas (17), (20), (30), and (32) that

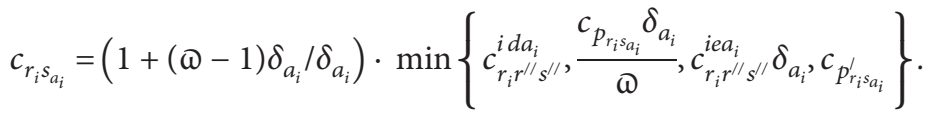

With the generalized transport cost of $i$ - th family members $a_{i}$ obtained in formulas (34) to (37) at hand, we can choose the coordinate function from formulas (34) to (37) with respect to the difference of both the family location and the destinations of the family members and finally get the generalized transport cost of the $i-$ th family as follows:

$$
c_{i}=\sum_{a_{i} \in A_{i}} c_{r_{i} s_{a_{i}}} .
$$

\section{Hedonic Cost of the Family}

Each family has a percentage of household income used for enjoyment and will add its hedonic cost with the increase of income. At the same time, the level of average family hedonic cost is different in different cities, and different locations family in the same city also has different hedonic cost. Let $\bar{\Omega}$ be all family average income levels every day in the city; the hedonic cost of the family is related to the household income 
level, and the hedonic cost in the city center is thus a function of $\bar{\Omega}$, which is denoted by $\chi^{0}(\bar{\Omega})$. Furthermore, the hedonic cost function is $\varepsilon \chi^{0}(\bar{\Omega})$ at the edge of the city, where $\varepsilon$ is the basic cost coefficient for maintaining family's living.

If the transportation for the city is only the conventional public transport, hedonic cost of the family is associated with family's position in the city. More precisely, the hedonic cost is the highest in city center and is inversely proportional to the distance to the city center.

Let $d^{k}$ be the distance between the city center and the $k$ - th district, $d^{0}$ is the semidiameter of the city, and the hedonic cost function $\chi^{k}$ for the $k$ - th district is a point on the line, which links $\chi^{0}(\bar{\Omega})$ with $\varepsilon \chi^{0}(\bar{\Omega})$. This means $\chi^{k}$ is a convex combination between $\chi^{0}(\bar{\Omega})$ and $\varepsilon \chi^{0}(\bar{\Omega})$. Thus, the hedonic cost of the district without rail transit station can be obtained as

$$
\chi^{k}=\left(1-\frac{d^{k}}{d^{0}}\right) \chi^{0}(\bar{\Omega})+\varepsilon \chi^{0}(\bar{\Omega}) \cdot \frac{d^{k}}{d^{0}} .
$$

Since rail transit will increase the regional accessibility along the rail way, economic activities in the region are attracted to rail transportation corridor. That is to say, the facilities completeness of the district with rail transits station is higher than the districts in the same location without rail transit station. Hence, the family's hedonic cost of the district with rail transit station is much higher due to the increasing accessibility and thus the shorter distance between the district and the city center. In order to illuminate this fact, the distance $d^{k}$ must be multiplied by a rail transit impact factor $\gamma$ if the $k$ - th district contains a rail transit station, which is expressed as $\left(1-\gamma d^{k} / d^{0}\right) \chi^{0}(\bar{\Omega})+$ $\varepsilon \chi^{0}(\bar{\Omega}) \cdot \gamma d^{k} / d^{0}$ with $0<\gamma \leq 1$. The impact factor $\gamma$ is inversely proportional to the ratio between the speed of rail transit and conventional traffic speed along the rail way. Indeed, $\gamma$ is the smaller when the ratio is bigger and that rail transit impacts accessibility of the $k$-th district more. When $\gamma=1$, the rail transit does not impact the district's accessibility. Besides, the completeness of district facilities also impacts the hedonic cost of the district families to some extent. This leads to the fact that $\chi^{k}$ must be amended again, which is achieved by multiplying a factor that is related to the hedonic facilities completeness $h^{k}$. Recalling that the hedonic facilities completenesses of the urban fringe district and the city center are $\varepsilon^{0}$ and 1 , respectively; we can calculate the hedonic facilities completeness of the $k$ - th district as

$$
h_{1}^{k}=\left(1-\frac{d^{k}}{d^{0}}\right) 1+\varepsilon^{0} \cdot \frac{d^{k}}{d^{0}} .
$$

However, this is not the real hedonic facilities completeness of the $k$-th district and is also named as the calculated completeness. Hence, the ratio between the real completeness $h^{k}$ and the calculated completeness $h_{1}^{k}$ can be used as the adjustment of the hedonic cost for hedonic facilities completeness. With the discussion stated above, the hedonic cost of the district with a rail transit station can be obtained as

$$
\chi^{k}=\left[\left(1-\gamma \frac{d^{k}}{d^{0}}\right) \chi^{0}(\bar{\Omega})+\varepsilon \chi^{0}(\bar{\Omega}) \cdot \gamma \frac{d^{k}}{d^{0}}\right] \cdot \frac{h^{k}}{h_{1}^{k}} .
$$

\section{Choice of Residence}

For the choice of residence, consumers always regard the family as a unit, and where to live is the optimal decision of the whole family. The factors that are considered when family chooses residential location include the total traffic impedance of all family members between the main activity location and residential location, hedonic facilities completeness of the district, residential housing prices of the district, and the family income. Each family will wish to choose the coordinate residence, which coincides with its income level. In other words, for some fixed income level, the family housing conditions are pursued as well as possible, the consumption of the hedonic aspects is as high as possible, and family daily traffic impedance is as low as possible. For the period time of $t$, it thus follows from the housing prices $p_{j m}^{k t}$, the hedonic cost $\chi^{k}$, and the total generalized transport cost $c_{i}$ of any family $i$ that the attraction of the $k$-th district to the family $i$ is

$$
z^{i k}=\frac{p_{j m}^{k t} \chi^{k}}{c_{i}}
$$

Let the gross income of family $i$ be $\Omega^{i}$ every day; it is rate $y$ for household total income, which composes of the families daily consumption for housing, hedonic, and transportation; $\mu$ is the sum of daily transportation expenses of family, which includes transportation fares and driving fuel consumption; it holds that

$$
p_{j m}^{k t}+\chi^{k}+\mu \leq \eta \Omega^{i}
$$

is the premise for family $i$, which chooses the $k$ - th district to be the residential location; i.e., the $k$ - th district is feasible to family $i$. Thus, we regard all of these districts as a feasible zone for family $i$ which is denoted by $K_{i}$. The family $i$ has its own satisfaction degree $\mu_{i}^{k}$ for the family housing of any district $k \in K_{i}$. The satisfaction degree is 1 for attractiveness largest housing and is decreased with reducing attractiveness.

Denoting

$$
z^{i}=\max _{k \in K_{i}}\left\{z^{i k}\right\}
$$

we will calculate the close degree of each district's housing attractiveness $z^{i k}$ and $z^{i}$ in $K_{i}$, which is regarded as the satisfaction degree of family $i$ to the district. The close degree is denoted by $\mathbb{R}\left(z^{i k}, z^{i}\right)$ which is expressed as

$$
\mathbb{R}\left(z^{i k}, z^{i}\right)=1-\frac{z^{i}-z^{i k}}{z^{i}},
$$

obviously, where $0 \leq \mathbb{R}\left(z^{i k}, z^{i}\right) \leq 1$. When district's housing attractiveness satisfies $z^{i k}=z^{i}$, the close degree reaches the maximum value of 1 . The difference between them is greater 
as the close degree is smaller. Thus, the satisfaction degree of that family $i$ can be obtained as

$$
\mu_{i}^{k}=\mathbb{R}\left(z^{i k}, z^{i}\right),
$$

for the housing in the $k$-th district.

It is well known that family $i$ has a satisfaction degree $\mu_{i}^{k}$ to the $k$-th district, which has the property that the satisfaction degree is larger as the value of the housing will be much higher in the $k$ - th district. On the contrary, the value for family $i$ is smaller. Moreover, the satisfaction degree influences the extent of family $i$ 's value, which has positive correlation with the house value. Therefore, if family $i$ has purchased one house in the $k$ - th district, family $i$ will then obtain the surplus value:

$$
U_{i}^{k}=M_{i j m}^{k t}-p_{j m}^{k t}\left(1-\mu_{i}^{k}\right)^{2} .
$$

Based on each district's housing prices and the housing satisfaction degree, the moving family chooses the residential location with the largest consumer surplus; i.e.,

$$
k_{i}=\arg \max _{k}\left(U_{i}^{k}-p_{j m}^{k t}\right) .
$$

Assuming that all families in the city have individual rationality, family $i$ chooses the $k$-th district to be the residential location under the condition that

$$
U_{i}^{k} \geq p_{j m}^{k t},
$$

meaning

$$
M_{i j m}^{k t}-p_{j m}^{k t}\left(1-\mu_{i}^{k}\right)^{2} \geq p_{j m}^{k t} .
$$

The prerequisite of transaction success needs to meet the price greater than or equal to costs; at the same time, transaction success also needs to meet the condition that the transaction price cannot be higher than the valuation of homebuyers for the house; that is,

$$
V_{j m}^{k t} \leq p_{j m}^{k t} \leq M_{i j m}^{k t} .
$$

Finally, it is also subject to family economic conditions; i.e.,

$$
p_{j m}^{k t}+\chi^{k}+\mu \leq \eta \Omega^{i} .
$$

Based on the analysis stated above in formulas (48)-(52), the nonlinear programming model can thus be read as

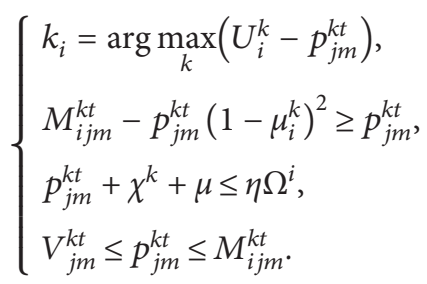

Now, we will solve the nonlinear programming model (53) and obtain the residential location $k^{*}$ with the largest surplus value for family $i$ and also the corresponding transaction prices $p_{j m}^{k t *}$ of house. We conclude that family $i$ will not move its home if there is no district that meets the condition.

\section{Algorithm}

The algorithm for rail transit and urban residential location choice relation model is as follows:

Step 1: given the initial value of all the various types of nonmoving residential location family numbers $\left|N_{1}^{k t}\right|$ and the moving residential location family numbers $\left|N_{2}^{k t}\right|$ in the district, according to $\left|N_{1}^{k t}\right|$ and $\left|N_{2}^{k t}\right|$, we will calculate all the OD demands $q^{r s}$, assign initial value to $p_{j m}^{k t}$, and set the traffic volume $f_{a}:=q_{a}^{0}$ on each road, where $k \in D, i \in N_{2}^{k t}$, and $a \in E$.

Step 2: if the OD demand is $q^{r s}>0$, calculate the traffic speed $v_{a}\left(f_{a}\right)$ of each road on all of the paths between $r$ and $s$; seek the path with the smallest traffic impedance between $r$ and $s$, expressed as

$$
p_{0}=\arg \min _{p} c_{p_{r s}} .
$$

Set

$$
q^{r s}:=q^{r s}-1 .
$$

Step 3: if $a_{0} \in p_{0}$, then

$$
f_{a_{0}}:=f_{a_{0}}+1,
$$

and calculate the passengers number of various traffic modes; if all $q^{r s} \leq 0$, then turn to step 4 ; else turn back to step 2.

Step 4: if $\left|N_{2}^{k t}\right|>0$, then

$$
\left|N_{2}^{k t}\right|:=\left|N_{2}^{k t}\right|-1,
$$

calculate

$$
\mu_{i}^{k}=\mathbb{R}\left(\alpha_{i}^{k}, \alpha_{i}\right),
$$

and solve formula (53) of the nonlinear programming model, so $k^{*}$ and $p_{j m}^{k t *}$ will be obtained.

Step 5: set

$$
\begin{aligned}
\left|N_{1}^{k^{*} t}\right| & :=\left|N_{1}^{k^{*} t}\right|+1, \\
p_{j m}^{k t} & :=p_{j m}^{k t *} .
\end{aligned}
$$

We will stop the calculation if all districts are subject to $\left|N_{2}^{k t}\right| \leq 0$ and will turn back to step 2 if not.

The algorithm contains two loops: one is inside and the other is outside. The inside loop is made up of step 1 and step 2 , which is to realize the OD distribution, road traffic impedance calculation, and transport means selection. If an OD demand distribution is end, then it will skip the OD allocation until all OD distributions are end in the cycle. The outside loop is all kinds of families that choose the residential location with the largest family surplus value by their own characteristics, until the selection of all categories of moving families in the district is over. 


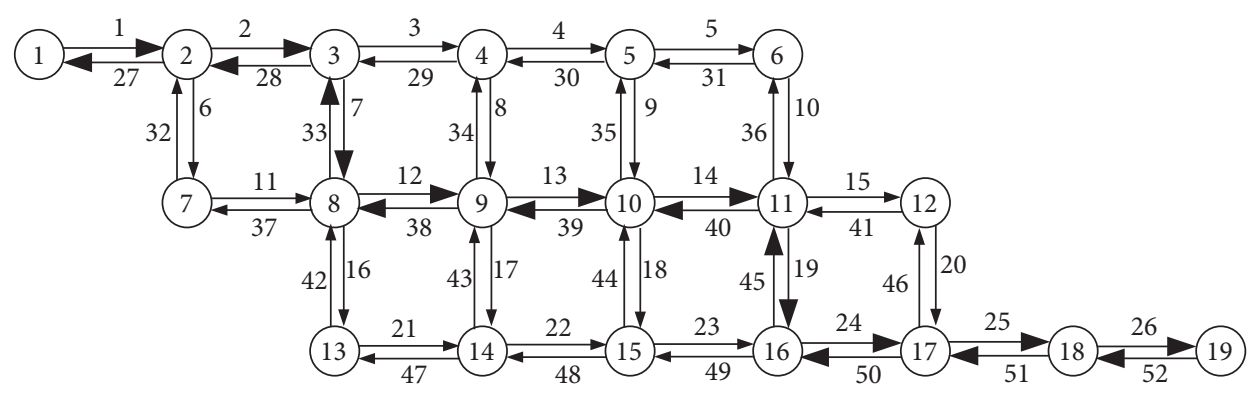

Figure 1: Simple traffic network.

\section{Example}

As is shown in Figure 1, this is a part of one city's transport network, which is divided into 19 (1 to 19) residential areas. There are four main destinations, 1, 19, 6, and 9 , where 9 is the city center area. There is a two-way road between the residential areas, the black line in the road network is also a rail transit, and the volume and free-flow speed of two opposite directions on each road are the same. The static data for the length, volume, and free-flow speed of each road are shown in Table 1.

For any residential area, there are commuters that go to the four destinations and then compose 76 OD demands. Take the family as a research unit and do not consider the commute inside the district, such as walking commuter, riding bicycle commuter, and other circumstances. Because the choice of family residential location concerns commuting distance, we only simulate it from the view of public transport and driving car. Each family has two members to go to the major destinations by a kind of traffic modes or the combination of multiple traffic modes. In addition to holiday, the frequency for each family member going to the major destinations is 1 .

According to the difference of the destinations for the family's two members, the families of each district are divided into 10 types: destination 9, destination 1 , destination 19, destination 6 , destinations 9 and 1 , destinations 9 and 19, destinations 9 and 6 , destinations 1 and 19, destinations 1 and 6, and destinations 19 and 6. These 10 types of families are distributed evenly among all types of families and distinguished by high-income family that has a private car and middle-low-income one that does not have private car. If the two destinations of the high-income family members are the same, then their daily commute is to carpool own car. If the destinations are different, then the car can only be used by the member of outlying destination district, and the other member commutes by public transportation. The car fuel fee is 0.65 yuan $\cdot \mathrm{km}^{-1}$. If the general cost of total travel is 2 times than that by rail transit, the owners of private car will take rail transit to go to the destination. Furthermore, private cars do not transfer with conventional public transport, and private car drivers do not choose conventional public transport commuter mode.

All members of middle-low-income families commute by public transportation, and all of the paths between each OD pair have conventional public transport that can meet the traffic demand. Let each bus go ahead $600 \mathrm{~m}$ for conventional public transport station. The passenger capacity per conventional public transport at the rush hour is 60 people, and the ticket price is 1 yuan. The average delay of both the conventional public transport stops at the station and the intersection is $60 \mathrm{~s}$. Let the train be made up of 8 block trains, and one-way passenger capacity in the rush hour is 30,000 passengers per hour, and the ticket price is 2 yuan. The bicycle storage cost is 1 yuan per vehicle at the rail station. In order to attract the car driver to transfer the rail transit, the parking fee at the rail station is 10 yuan per vehicle. The time for passengers walking from the rail transit station's entrance to the rail station's platform is 6 minutes, which includes buying the ticket. It takes 4 minutes for passenger to exit the rail transit station. The departure frequency of the rail transit at the rush hour is $12 \mathrm{veh} \cdot \mathrm{h}^{-1}$. Next, we will assume some known data as follows: the average speed of walking is $1.25 \mathrm{~m} \cdot \mathrm{s}^{-1}$, the average speed of riding bicycle is $20 \mathrm{~km} \cdot \mathrm{h}^{-1}$, rail transit stations located in a going-through residential area, the running speed of rail vehicle between two rail adjacent stations is $120 \mathrm{~km} \cdot \mathrm{h}^{-1}$, and the average delay that rail transit vehicle decelerates, docks the platform, and accelerates at one rail station is $60 \mathrm{~s}$. Finally, the completeness of hedonic facilities, the total number of families, the proportion of high-income families, and the number of all types of families in each district are shown in Table 2.

The numerical value corresponding to the relationship between traffic flow/volume and average speed/free flow speed is shown in Table 3 [28].

Fixing the study period time to be one year, the monthly housing costs evaluation $M^{0}$ in the city center is 4,000 yuan (calculated by 20 years). The proportionality coefficient $c_{0}$ is $1 / 30$. The monthly per capita income level of the city is 2,400 yuan, and the work per weekday is 8 hours. The monthly incomes of high-income family and middle-low-income one are 12,000 yuan and 6,000 yuan, respectively. Assume that the ratio of moving demand families in each residential area is $20 \%$, it is rate $70 \%$ for household total income. The hedonic cost $\chi^{0}$ in the city center is 2,000 yuan; the basic living cost coefficient for maintaining family is $\varepsilon=0.5$. The housing supply is enough in each district, which contains a certain number of high-grade housings to meet the highincome families' demand whose price is 1.2 times than that of the ordinary housing. Let the initial traffic saturation be 0.8 on the outlet inlet main roads $25,26,27,1,51$, and 52 in 
TABle 1: Static attributes of the simple traffic network.

\begin{tabular}{|c|c|c|c|c|c|c|c|c|c|c|c|c|c|}
\hline Road & 1,27 & 2,28 & 3,29 & 4,30 & 5,31 & 6,32 & 7,33 & 8,34 & 9,35 & 10,36 & 11,37 & 12,38 & 13,39 \\
\hline Length $(\mathrm{km})$ & 8 & 6 & 2.9 & 3.5 & 4 & 5 & 3.87 & 4 & 3 & 5 & 5 & 3.2 & 3 \\
\hline Volume $\left(\mathrm{veh} \cdot \mathrm{h}^{-1}\right)$ & 3000 & 3000 & 4000 & 3000 & 2000 & 2000 & 3000 & 4000 & 3000 & 2000 & 2000 & 4000 & 4000 \\
\hline Free-flow speed $\left(\mathrm{km} \cdot \mathrm{h}^{-1}\right)$ & 50 & 50 & 60 & 50 & 30 & 30 & 50 & 60 & 50 & 30 & 30 & 60 & 60 \\
\hline Road & 14,40 & 15,41 & 16,42 & 17,43 & 18,44 & 19,45 & 20,46 & 21,47 & 22,48 & 23,49 & 24,50 & 25,51 & 26,52 \\
\hline Length $(\mathrm{km})$ & 3 & 6 & 4 & 3.5 & 3.72 & 3.5 & 4.5 & 3 & 3.8 & 5 & 4 & 4.5 & 10 \\
\hline Volume $\left(\mathrm{veh} \cdot \mathrm{h}^{-1}\right)$ & 4000 & 3000 & 3000 & 4000 & 3000 & 4000 & 3000 & 3000 & 2500 & 4000 & 4000 & 4000 & 3000 \\
\hline Free-flow speed $\left(\mathrm{km} \cdot \mathrm{h}^{-1}\right)$ & 60 & 50 & 50 & 60 & 50 & 60 & 50 & 50 & 30 & 60 & 60 & 60 & 50 \\
\hline
\end{tabular}

the rush hours, and the initial saturation of the other road traffic is 0.4. According to the different cases for whether there is rail transit between districts 18 and 19 or not, we use the consumer surplus model to simulate the choice of moving families as regards where to live, and the results are shown in Tables 4 and 5, respectively.

When there is rail transit between districts 18 and 19, the result that moving families choose the residential location is given in Table 4. It shows that both the high-income and middle-low-income moving families with their single commuter destination being 1,19 , and 6 will choose the residential location in the destination district. The district is located in suburban area, and the housing price is cheap. If they choose the destination district as the residential location, the commute traffic impedance is the smallest and the consumer surplus value is the largest for the families. For the high-income moving families with their destination being 9, since the family economic conditions can undertake the high housing price in the city center, families choose to live in the commuter destination district 9, where their traffic impedance is the smallest, and the consumer surplus value is the largest. However, for the middlelow-income moving families with their destination being 9 , since they cannot afford the high housing price in the city center, these families will choose the residential location with high accessibility rail transit and much lower housing price to make their consumer surplus value be the largest, such as destination 8 or 10 .

If the family has two commuter destinations, according to consumer surplus maximum principle, both high-income families and middle-low-income ones have chosen to live in one of the two destinations. If the two destinations of highincome families are in the suburban area and in the city center, respectively, according to the consumer surplus maximum principle, they will choose the residential location in the suburban area; for example, the moving families whose destinations are 9 and 1,9 and 6 , and 9 and 19 will choose districts 1,6 , and 19 , respectively. If the two destinations of middle-low-income families are in the suburban area and in the city center, respectively, according to the consumer surplus maximum principle, if suburban commuter destination contains high accessibility rail transit, then most of families will choose their residence in the city center with the same rail transit, and fewer families will choose the commuter destination in the suburbs. If the destination of suburban area has no rail transit station, then a large proportion of families choose to live in the commuter destination district in the suburban area. If the two commuter destinations of families are in the suburban area, both the high-income and the middle-low-income moving families will choose to live in one of the two destinations, where the rail transit station is located. For example, the moving family's residential location whose destination is 1 and 19 will choose district 19 , the moving family's residential location whose destination is 1 and 6 will choose district 1 , and the moving family's residential location whose destination is 6 and 19 will choose district 19 .

When there is no rail transit between districts 18 and 19, the result where moving families choose the residential location is shown in Table 5. Compared with Tables 4 and 5 showing the following results, when there is no rail transit between districts 18 and 19, there is no effect on the residential location choice for high-income families in the city. If moving families have one single commuter destination or two commuter destinations located in the suburb, there is no effect on the residential location choice of middle-low-income moving families too. For the middle-low-income families whose two destinations are located in the suburban area and city center, respectively, if the commuter route do not pass the road between districts 18 and 19 , then it has a little impact on the moving families to choose their residential location, for example, when the family's commuter destinations are 9 and 6 and 9 and 1 . If the commuter route passes the road between districts 18 and 19 , whether there is rail transit between districts 18 and 19 or not, then it has appreciable impact on the moving family as to how to choose its residential location. If there is a rail transit between districts 18 and 19, then most of middle-low-income moving families with their destinations being 9 and 19 will choose their residence located in city center; indeed, there are 1460 middle-low-income moving families choosing district 9 as their residence, and 942 middle-low-income moving families choosing district 19 as their residence. If there is no rail station between districts 18 and 19, most of middle-lowincome moving families with their destinations being 9 and 19 will choose their residence located in the suburban area; indeed, there are 133 middle-low-income moving families choosing district 9 as their residence and 2181 middle-lowincome moving families choosing district 19.

In a word, all of high-income moving families choose their residential location located in the commuter destination district and prefer to choose the commuter destination as their residence in the suburban area. This is due to the higher income of these families, and the families own private cars; thus the accessibility that they go to other districts is much higher, so they obtained the largest consumer surplus value. In addition to the middle-low-income family of one 


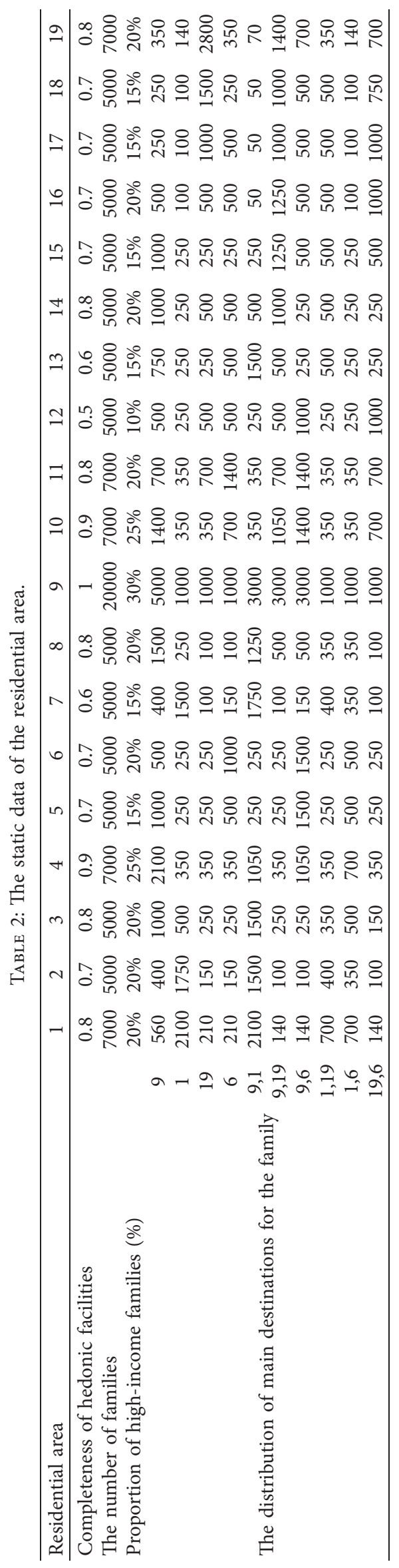


TABLE 3: The relationship between vehicle's average speed and path flow.

\begin{tabular}{|c|c|c|c|c|c|c|c|c|c|c|c|}
\hline Traffic flow/volume & $\leq 0.3$ & 0.4 & 0.5 & 0.6 & 0.7 & 0.8 & 0.9 & 1.0 & 1.1 & 1.2 & $\geq 1.3$ \\
\hline Average speed/free-flow speed & 1 & $34 / 35$ & $31 / 35$ & $24 / 35$ & $19 / 35$ & $14 / 35$ & $9 / 35$ & $4 / 35$ & $3 / 35$ & $2 / 35$ & 0 \\
\hline
\end{tabular}

TABLE 4: Mobile families choose the result of residential location with rail transport between districts 18 and 19.

\begin{tabular}{lcccccccccccccc}
\hline Class of family destination & & 9 & & 1 & 19 & 6 & 9 and 1 & 9 and 19 & 9 and 6 & 1 and 19 & 1 and 6 & 6 and 19 \\
\hline $\begin{array}{l}\text { The number of } \\
\text { middle-low-income families }\end{array}$ & 1725 & 0 & 1254 & 1620 & 1781 & 1469 & 156 & 2389 & 1850 & 464 & 1460 & 942 & 1342 & 1127 \\
$\begin{array}{l}\text { The number of } \\
\text { high-income families }\end{array}$ & 0 & 857 & 0 & 404 & 427 & 368 & 677 & 0 & 0 & 609 & 640 & 0 & 331 & 296 \\
\begin{tabular}{l} 
Selected district \\
\hline
\end{tabular} & 8 & 9 & 10 & 1 & 19 & 6 & 1 & 9 & 9 & 19 & 6 & 9 & 19 & 1 \\
\hline
\end{tabular}

TABle 5: Mobile families choose the result of residential location with no rail transport between districts 18 and 19 .

\begin{tabular}{|c|c|c|c|c|c|c|c|c|c|c|c|c|c|c|c|}
\hline \multirow{2}{*}{$\begin{array}{l}\text { Class of family destination } \\
\text { The number of } \\
\text { middle-low-income families }\end{array}$} & \multirow[b]{2}{*}{1725} & \multicolumn{2}{|l|}{9} & \multirow{2}{*}{\begin{tabular}{c|}
1 \\
1620
\end{tabular}} & \multirow{2}{*}{$\frac{19}{1781}$} & \multirow{2}{*}{$\frac{6}{1469}$} & \multicolumn{2}{|c|}{9 and 1} & \multicolumn{2}{|c|}{9 and 19} & \multicolumn{2}{|c|}{9 and 6} & \multirow{2}{*}{$\begin{array}{c}1 \text { and } 19 \\
1342\end{array}$} & \multirow{2}{*}{$\begin{array}{c}1 \text { and } 6 \\
1127\end{array}$} & \multirow{2}{*}{$\begin{array}{c}6 \text { and } 19 \\
1507\end{array}$} \\
\hline & & 0 & 1254 & & & & 96 & 2449 & 133 & 2181 & 1473 & 929 & & & \\
\hline $\begin{array}{l}\text { The number of } \\
\text { high-income families }\end{array}$ & 0 & 857 & 0 & 404 & 427 & 368 & 677 & 0 & 0 & 609 & 640 & 0 & 331 & 296 & 356 \\
\hline Selected district & 8 & 9 & 10 & 1 & 19 & 6 & 1 & 9 & 9 & 19 & 6 & 9 & 19 & 1 & 19 \\
\hline
\end{tabular}

single commuter in destination 9, the middle-low-income moving families also choose the commuter destination as their residence located in the suburban area. If the middlelow-income families' two commuter destinations are located in the suburban area, then they prefer to choose the commuter destination district with the rail transit of high accessibility. The middle-low-income families with one single commuter in destination 9 choose their residence near the city center with rail transit of high accessibility. The reason for this is that the lower-income families do not have private cars and thus go to other districts only by the public transport. The completeness of public traffic facilities is the highest in the city center, and it has high accessibility, while the districts with rail transit station have high accessibility. Therefore, they integrated family income, house prices, district facilities completeness, hedonic cost, and other factors and thus choose residence located with the largest consumer surplus value. Whether a road has rail transit or not has a significant impact on the middle-low-income families choosing their residence located when the commuter route passes the road, while it almost does not have impact on the other families.

Figure 2 shows the contrast of the commuter usage percentage for cars in each district, when there is rail transit between districts 18 and 19 or not. We can know the following: the commuter usage percentage of cars has obviously changed in districts $4,5,7,8,9,10,11$, and 19 , and there is a smaller change in the remaining districts. More precisely, when there is not rail transit between district 18 and 19, these significant changes happened district $(4,5,7,8,9,10,11$ and 19), and high-income families whose commuter destination district is 19 , the commuter usage of cars increase $29 \%, 39 \%, 13.6 \%, 16 \%$, $5 \%, 27 \%, 19 \%$ and $5 \%$ respectively, comparing with the case that there is rail transit between district 18 and 19.comparing with the case that there is rail transit between district

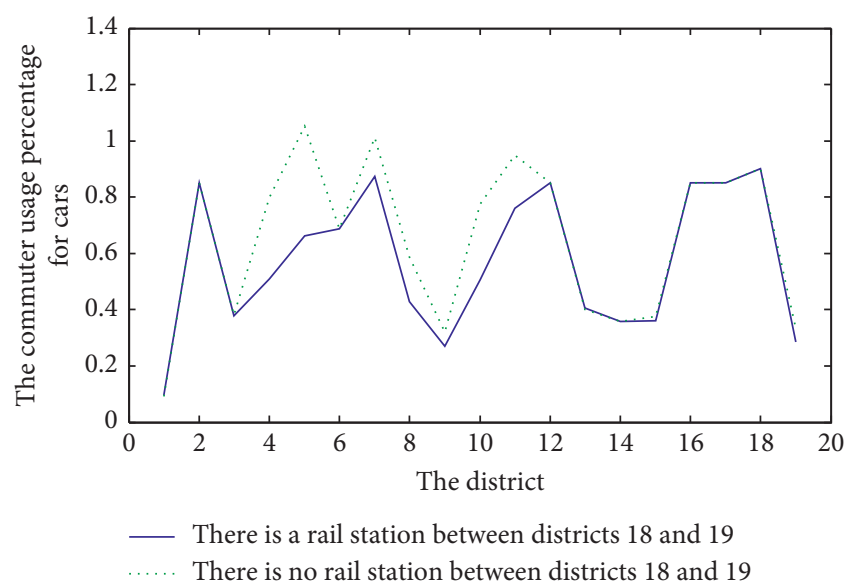

Figure 2: Car commuter rate in each district.

18 and 19, comparing with the case that there is rail transit between district 18 and 19. Indeed, this is because the distance between destination 19 and these districts is much bigger; if there is rail transit between districts 18 and 19, the accessibility that the family goes to destination district 19 from these districts by conventional public transport and then transfers to rail transit or direct rail transit is much higher than that by driving private car. However, if there is no rail transit between districts 18 and 19, the accessibility that the family goes to destination district 19 by conventional public transport will decrease, and the commuters of the high-income families will thus drive private cars in this case for the lowly comfortable degree and other reasons. Since districts 1, 2, and 3 are very far from 19 district, the general transportation cost of driving commuter is much higher. Notice that districts 1,2, and 3 have rail transit station; whether there is rail transit between districts 18 and 19 or not, the high-income earners whose commuter 


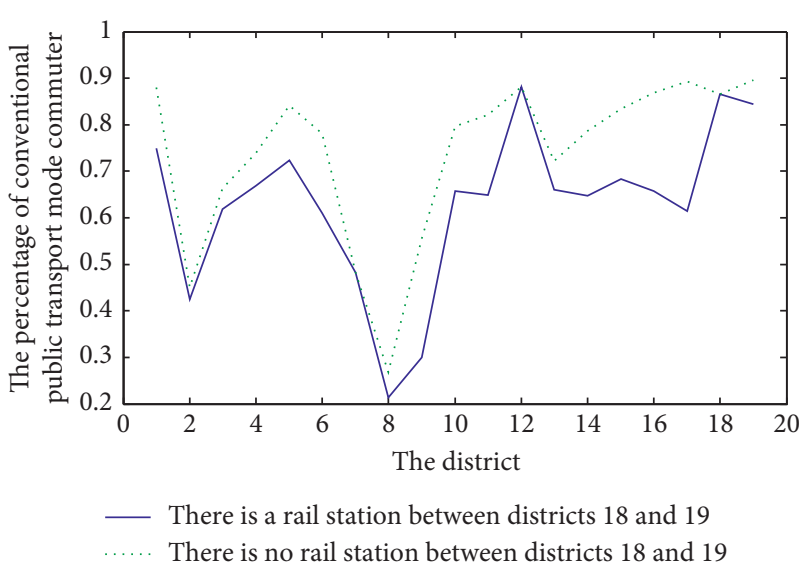

FIgURE 3: Conventional public transport commuter rate of residents in each district.

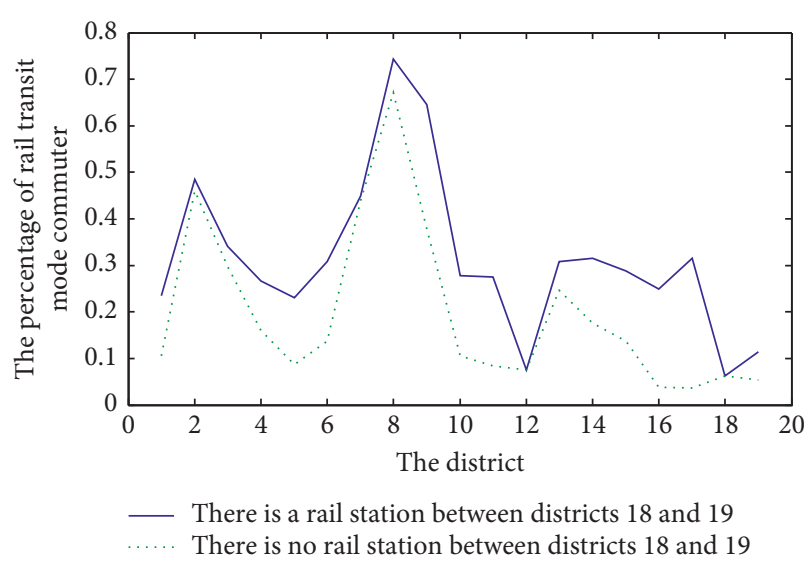

FIgURE 4: Rail transport commuter rate of residents in each district.

destination is district 19 will choose rail transit or rail transit transfer instead of conventional public transport to commute. The remaining districts are not in rail transit line but are close to district 19; the number of high-income earners commuting district 19 by the rail transit modes is much smaller; therefore, whether there is rail transit between districts 18 and 19 or not, the commuter usage percentage of cars has a small change in these districts.

It is shown from Figures 3 and 4 that as the rail transit between districts 18 and 19 is changed from nonexistence to existence, the percentage of rail transit mode commuter has increased almost in all districts, and the percentage of conventional public transport mode commuter has decreased correspondingly.

If there is no rail transit between districts 18 and 19 , the rail transit commuting percentage of residents in districts 4 , $9,11,16$, and 17 has decreased by $21 \%, 27 \%, 29 \%, 21 \%$, and $28 \%$, respectively, in comparison to the case where there is rail transit between districts 18 and 19 . The rail transit commuting percentage of residents in districts $1,5,6,10,14$, and 15 has decreased by $10 \sim 20 \%$, the rail transit mode commuter number in the other districts has decreased by $1 \sim 10 \%$ at the same time, and all of these residents change their transport mode from rail transit to conventional public transport. Thus, the reasonableness for the design of the part of an urban road network will influence not only residents choosing their transport mode in a part of the city but also transport mode and traffic behavior of the whole city's residents.

The example shows the importance of reasonable urban planning, as well as the important role of rail transit in urban public transport systems. At the same time, we find that one single rail transit line cannot meet the requirements of the transport mode backbone. The primary reason is the limitations of the passenger flow attracted scope and the line route directions. Thus, rail transit has to form a network and thus will play a key role in the whole traffic network.

\section{Conclusions}

The relationship model between residential location selection and rail transit system is discussed in the paper. We have established the impedance model with the traffic connects each other between various transportation modes, so the general traffic impedance of each family is obtained. The choice of living location is the optimal decision of the whole family. Considering the factors of the household income, the workplace characteristics of members, the generalized traffic impedance of the family, the facility structure of each district, and housing price, each mobile family will choose destination district as the residential location with the largest consumer surplus value. Urban traffic structure has been optimized by rail transit. Indeed, the residents prefer to live in a specific location if the destination district has rail station, and this may decrease the traffic demand of the city and optimize the urban spatial structure. At the same time, the city manager could guide residents to choose their residence location by attracting more businesses and enterprises to the district with rail station, which improved the structure of urban space to be more perfect.

\section{Data Availability}

The data used to support the study are included within the article.

\section{Conflicts of Interest}

The author declares that there are no conflicts of interest.

\section{Acknowledgments}

This research was supported by the National Natural Science Foundation of China (no. 51368046) and Natural Science Foundation of Jiangxi Province, China (no. 20151BAB201028).

\section{References}

[1] Y. Enjian and M. Takayuki, "A study of an integrated intercity travel demand model," Transportation Research Part A: Policy and Practice, vol. 39, pp. 367-381, 2005. 
[2] L. B. Li, M. Wang, Z. Dong et al., "Method of parking index based on parking function and location conditions," China Journal of Highway and Transport, vol. 23, no. 1, pp. 111-115, 2010.

[3] J. S. Chang and R. L. Mackett, "A bi-level model of the relationship between transport and residential location," Transportation Research Part B: Methodological, vol. 40, no. 2, pp. 123-146, 2006.

[4] F. Tao, J. Y. Zhang, F. Akimasa et al., "An integrated model system and policy evaluation tool for maximizing mobility under environmental capacity constraints: a case study in Dalian City, China," Transportation Research Part D: Transport and Environment, vol. 15, pp. 263-274, 2010.

[5] R. B. Chandra and Y. G. Jessica, "A comprehensive analysis of built environment characteristics on household residential choice and auto ownership levels," Transportation Research Part B: Methodological, vol. 41, pp. 506-526, 2007.

[6] L. Zhen, "Modeling of yard congestion and optimization of yard template in container ports," Transportation Research Part B, vol. 90, pp. 83-104, 2016.

[7] A. R. Pinjari, C. R. Bhat, and D. A. Hensher, "Residential selfselection effects in an activity time-use behavior model," Transportation Research Part B: Methodological, vol. 43, no. 7, pp. 729-748, 2009.

[8] D. Earnhart, "Combining revealed and stated data to examine housing decisions using discrete choice analysis," Journal of Urban Economics, vol. 51, no. 1, pp. 143-169, 2002.

[9] L. Zhen, "Tactical berth allocation under uncertainty," European Journal of Operational Research, vol. 247, no. 3, pp. 928-944, 2015.

[10] L. Zhang, W. Du, and Q. Q. Guo, "Negotiation mechanism model of relationship between residential location and traffic system," Journal of Traffic and Transportation Engineering, vol. 10, no. 6, pp. 102-109, 2011.

[11] M. Wegener, "Operational urban models state of the art," Journal of the American Planning Association, vol. 60, no. 1, pp. 17-29, 1994.

[12] J. R. Roy and J.-C. Thill, "Spatial interaction modelling," Fifty Years of Regional Science, vol. 83, pp. 339-361, 2004.

[13] P. Silveira and T. Dentinho, "Spatial interaction model of land use - an application to Corvo Island from the 16th, 19th and 20th centuries," Computers, Environment and Urban Systems, vol. 34, no. 2, pp. 91-103, 2010.

[14] T. P. Dentinho and P. Silveira, "Spatial interaction model with land use to analyse the impact of designed accessibilities," in Proceedings of the 8th world congress of RSAI 2008 an Application to Corvo Island from XVI, XIX and XX Centuries, Sao Paulo, Brazil, 2008.

[15] A. Anas and R. Xu, "Congestion, land use, and job dispersion: a general equilibrium model," Journal of Urban Economics, vol. 45 , no. 3, pp. 451-473, 1999.

[16] A. Anas, "The optimal pricing, finance and supply of urban transportation in general equilibrium: a theoretical exposition," Economics of Transportation, vol. 1, no. 1-2, pp. 64-76, 2012.

[17] A. Anas and T. Hiramatsu, "The economics of cordon tolling: general equilibrium and welfare analysis," Economics of Transportation, vol. 2, no. 1, pp. 18-37, 2013.

[18] E. Murphy, "Urban spatial location advantage: the dual of the transportation problem and its implications for land-use and transport planning," Transportation Research Part A: Policy and Practice, vol. 46, no. 1, pp. 91-101, 2012.
[19] M.-J. Jun, "Redistributive effects of bus rapid transit (BRT) on development patterns and property values in Seoul, Korea," Transport Policy, vol. 19, no. 1, pp. 85-92, 2012.

[20] M.-J. Jun, "The effects of housing preference for an apartment on residential location choice in Seoul: a random bidding land use simulation approach," Land Use Policy, vol. 35, pp. 395405, 2013.

[21] K. W. Kelvin, S. C. Yim, A. Wonga, A. Chen et al., "A reliability-based land use and transportation optimization model," Transportation Research Part C, vol. 19, pp. 351-362, 2011.

[22] P. Coppola and A. Nuzzolo, "Changing accessibility, dwelling price and the spatial distribution of socio-economic activities," Research in Transportation Economics, vol. 31, no. 1, pp. 63-71, 2011.

[23] B. Farooq and E. J. Miller, "Towards integrated land use and transportation: a dynamic disequilibrium based microsimulation framework for built space markets," Transportation Research Part A: Policy and Practice, vol. 46, no. 7, pp. 1030-1053, 2012.

[24] Y. Kantor, P. Rietveld, and J. van Ommeren, "Towards a general theory of mixed zones: the role of congestion," Journal of Urban Economics, vol. 83, pp. 50-58, 2014.

[25] B. Zhou and K. Kockelman, "Micro-simulation of residential land development and household location choices: bidding for land in Austin, Texas," Transportation Research Record, vol. 2077, pp. 106-112, 2008.

[26] X. Ma and H. K. Lo, "Modeling transport management and land use over time," Transportation Research Part B: Methodological, vol. 46, no. 6, pp. 687-709, 2012.

[27] T. T.-L. Chong, K. C.-W. Shui, and V. H. Wong, "The nexus between labor wages and property rents in the Greater China area," China Economic Review, vol. 30, pp. 180-191, 2014.

[28] S. Markose, A. Alentorn, D. Koesrindartoto, P. Allen, P. Blythe, and S. Grosso, "A smart market for passenger road transport (SMPRT) congestion: an application of computational mechanism design," Journal of Economic Dynamics and Control, vol. 31, no. 6, pp. 2001-2032, 2007. 